\title{
A long-term follow-up of respiratory symptoms and ventilatory function in a group of working men
}

\author{
PETER HOWARD
}

The University Department of Medicine, The Royal Hospital, Sheffield, S1 3SR

\begin{abstract}
Howard, Peter (1970). Brit. J. industr. Med., 27, 326-333. A long-term follow-up of respiratory symptoms and ventilatory function in a group of working men. Out of a group of 289 industrial workers, 159 have been studied for a period of 11 years beginning in 1956. The mean rate of fall of FEV 0.75 was 0.034 litre/year and the rate of fall of FVC was 0.064 litre/year. There was little change in the FEV \% FVC over the period. Sudden drops of FEV were observed in a few men. Between 1956 and 1962 the number of men with regular sputum expectoration increased, but after 1962 more men lost this symptom than acquired it. The FEV was often markedly reduced by the time regular symptoms of bronchitis appeared. It seemed likely that symptomatic evidence of bronchial inflammation and infection and smoking were not related to the loss of ventilatory capacity in most men. Factors considered important to the genesis of airways obstruction, such as smoking, bronchial inflammation, atmospheric pollution and occupation, may differ in their importance in different environments. In this study atmospheric pollution was probably the most important factor.
\end{abstract}

The production of sputum is now accepted as the basic diagnostic criterion of chronic bronchitis (Ciba report, 1959). The disability from chronic bronchitis lies, however, not so much with the production of sputum but with the repeated chest illnesses and ventilatory impairment which are so often associated with it. Severe breathlessness, incapacity for work and death from respiratory failure or cor pulmonale ensue in a proportion of patients. The Medical Research Council's (1965) Committee on the Aetiology of Chronic Bronchitis defined the disease and divided it into three subtypes. The first, or simple bronchitis, was recognized by the regular production of sputum for defined periods of time; secondly, mucopurulent bronchitis was separated by the presence of pus continuously or intermittently in the sputum; and, thirdly, in chronic obstructive bronchitis widespread narrowing of the bronchial airways was present to cause an increased resistance to airflow. The forced expiratory volume (FEV) was recommended as a simple reproducible test which is believed to parallel obstruction of the airways.

Prevalence studies have demonstrated a broad relationship between persistent sputum production, liability to acute chest illnesses and ventilatory impairment as measured by the FEV (Fletcher, Elmes, Fairbairn, and Wood, 1959; Elmes, Dutton, and Fletcher, 1959; Brinkman and Coates, 1963; Stuart-Harris and Hanley, 1957). It has been assumed that there is a cause and effect relationship between these features of chronic bronchitis but their mere association in time does not necessarily indicate this. This study reports a follow-up of chest symptoms and the FEV in a group of working men during a period of 11 years. The change of symptoms and of the FEV with time have been analysed independently and their interrelationships have been examined.

\section{Methods}

The population studied was drawn from a large engineer- 
ing works situated near to the centre of Sheffield. Over the period a total of about 2600 men were employed at the works and a group of 400 of them had been investigated in 1951 (Stuart-Harris and Hanley, 1957). In 1956 a call for volunteers for a follow-up study yielded 289 men out of the investigated group. All 289 were studied in 1956; most considered themselves in good health but some had respiratory symptoms; 159 of these 289 were followed up.

In 1956 the men answered a questionnaire on respiratory symptoms and were examined physically, and the $\mathrm{FEV}_{\mathbf{0 . 7 5}}$ and forced vital capacity (FVC) were measured with a Collins-Gaensler spirometer. They were not seen again until 1962 when the Medical Research Council's (1960) first standard questionnaire of respiratory symptoms became available. The $\mathrm{FEV}_{\mathbf{0 . 7 5}}$ was measured with a Poulton spirometer (McKerrow, McDermott, and Gilson, 1960). Further follow-up studies were made in 1965, 1966, and 1967 using the standard questionnaire and the Poulton spirometer.

The analysis of symptoms was concentrated on the period from 1962 onwards when the standard questionnaire was used. Gain or loss of sputum expectoration, chest illnesses, and breathlessness were considered. Sputum was regarded as 'significant' when experienced regularly each morning and/or throughout the day on most days for more than three months of the year. For chest illnesses there had to be two or more episodes causing absence from work as defined in the standard questionnaire during a period of three years. Breathlessness was considered when sufficiently severe to limit the individual to walking at his own pace on the level. Sputum expectoration alone was considered in 1956 when the form of the questionnaire enabled some comparison to be made with the Medical Research Council questionnaire. In 1956 questions about the sputum habit included a complete denial of symptoms, intermittent occurrence with colds or at other times, regular morning sputum and regular morning and daily sputum. Only those grades of a complete denial of symptoms and of regular morning or daily sputum were considered. Men who denied sputum at any time were probably a more exclusive group than those classified as having no sputum on the MRC questionnaire because the occasional occurrence of sputum is included in the latter. Thus it was felt that if any man who denied sputum in 1956 admitted to it on a regular basis in 1962 or subsequently, it would indicate a meaningful acquisition of the symptoms of chronic bronchitis. The questions in 1956 on breathlessness and chest illnesses were not comparable with those used in later surveys and have therefore been ignored for this particular year.

The Poulton and Collins-Gaensler spirometers were compared using measurements on 40 men, and no significant difference was found between readings on each instrument $(t=16 \cdot 6, \mathrm{P}<0.001)$.

A graph of the FEV against time was plotted for each man. Individual regression coefficients of the change of FEV and FVC against time were calculated. For the majority of the follow-up group 5 points were available, but in a small number only 3 or 4 were possible due to occasional non-attendance. The minimum period of follow-up considered satisfactory was thus 9 years but for the majority it was 11 years.

\section{Results}

\section{Population changes}

In 1956289 men were seen; 99 were not seen again, but 87 were known to be alive in 1967. There was doubt about the other 12 . Of those who were followed up, 159 were studied fully, including 2 who died in 1967. The remaining 31 died between 1956 and 1967. The expected death rate calculated from a life table using the Registrar General's data (1951) for a male urban population of the same age structure was 50 deaths. It is certain that some of the untraced persons would have died, making the disparity between the observed and expected death rate less. A chi-square test on the difference between 33 deaths and 50 deaths was not significant. Thus, in broad terms, the group did not have an adverse mortality experience. In 7 cases chronic bronchitis or cor pulmonale secondary to it was listed as the prime cause of death, in 1 it was status asthmaticus and in 3 carcinoma of the lung. In 3 other instances chronic bronchitis was listed as a contributory cause of death. The cause of death was not known in 2 persons.

\section{Age and changes in FEV and FVC}

The mean age of the group of 159 was 42 $(\mathrm{SD}= \pm 9.0)$ years in 1956 and was slightly younger than that of the 99 men not seen (47 years $\pm 11.9 ; t=3.71, \mathrm{P}<0.001)$. Those who died were older, $56 \pm 8.8$ years in 1956 . The mean initial FEV in 1956 was $2.78 \pm 0.63$ litres for the 159 men, $2.65 \pm 0.84$ litres for the 99 men not seen, which was not significantly different, and $2 \cdot 15$ litres $\pm 1 \cdot 0$ for those who died. This latter figure was significantly lower than both previous figures but was almost entirely due to the age difference (allowing for age, mean value would be 2.63 litres). Twenty-three had a positive and 136 a negative regression coefficient of the change of FEV with time in years. The mean regression coefficient for the follow-up group was -0.034 litre \pm 0.038 per year. The regression coefficient was significantly correlated with the mean FEV during the follow-up period obtained by summing individual values and dividing by their number (Oldham, 1962). A lower mean FEV was associated with a greater rate of decline $(r= \pm 0.453$; $t=6.3 ; \mathrm{P}<0.001)$.

The deterioration of the FEV was also studied by calculating the regression of the FEV on age at each year of study. Table 1 shows the figures. As the population aged, the rate of loss of FEV increased. The mean figure of -0.034 litre per year obtained from the analysis of individual regression coefficients presumably includes this age effect. A change of age distribution in the follow-up group did not account for this age effect.

The rate of loss of FVC was $0.064 \pm 0.041$ litre/ year. Only seven patients showed an increase of vital capacity during the study. The loss of FVC was 
TABLE 1

REgRESSION OF FEV $_{0.75}$ AND FVC ON AgE at Each Year of Study

\begin{tabular}{|c|c|c|c|c|}
\hline \multirow{2}{*}{ Year } & \multirow{2}{*}{$\begin{array}{c}\text { No. of } \\
\text { men }\end{array}$} & \multirow{2}{*}{$\begin{array}{c}\text { Mean age } \\
(y r)\end{array}$} & \multicolumn{2}{|c|}{ Mean regression coefficient } \\
\hline & & & $\begin{array}{c}F E V \\
\text { (litres/yr) }\end{array}$ & $\begin{array}{c}F V C \\
(\text { litres } / y r)\end{array}$ \\
\hline $\begin{array}{l}1956 \\
1962 \\
1965 \\
1966 \\
1967\end{array}$ & $\begin{array}{l}159 \\
156 \\
143 \\
138 \\
134\end{array}$ & $\begin{array}{l}42 \\
49 \\
51 \\
52 \\
52\end{array}$ & $\begin{array}{l}-0.036 \\
-0.039 \\
-0.037 \\
-0.049 \\
-0.044\end{array}$ & $\begin{array}{l}-0.042 \\
-0.037 \\
-0.039 \\
-0.055 \\
-0.051\end{array}$ \\
\hline
\end{tabular}

almost twice that of the FEV. The FEV\% FVC fell slightly from $67.5 \%$ in 1956 to $63 \%$ in 1967 , suggesting that the increased rate of fall of FVC was simply due to differences in starting value. Regressions of FVC on age at each year of study (Table 1) also showed an increase as the population aged and this too was more marked than that of the FEV.

\section{Analysis of symptoms}

Out of 159 men 41 admitted a persistent daily sputum habit in 1956 (Table 2); 29 more acquired this symptom by 1962 and 7 lost it. These figures are in sharp contrast with those for the following period up to 1967 when 26 claimed to have stopped producing sputum and only 9 acquired the habit. These changes were statistically significant $(P<0.05)$. Thus there does seem to have been a considerable improvement in the experience of sputum expectoration in recent years. Changes in age distribution were not sufficient to explain these observations. Although numbers are small, there was also an improvement in the experience of acute chest illnesses after 1962. In 1962 there were 19 men with breathlessness which limited them to walking at their own pace on the level or more severe disability. Men with breathlessness arising from disease other than in the lungs were excluded from this classification. Only 2 men claimed to have lost breathlessness and 9 men acquired it between 1962 and 1967. Two men who were already breathless in 1962 complained of increased breathlessness in 1967. There was no evidence that the decrease of other symptoms of bronchitis after 1962 was associated with reduced breathlessness.

Figure 1 shows the distribution of regression coefficients of FEV and the number of men with persistent sputum in 1962. More men have sputum at the higher rates of decline than at the lesser rates. In Table 3 the mean FEV in 1962 and regression coefficient are compared for those who expectorated throughout the study and for those who lost or acquired sputum. There were no age differences between groups. Men who claimed a sputum habit throughout the study had a significantly higher rate of loss of FEV ( -0.049 litre/year) than the group as a whole $(-0.034$ litre/year), and this difference was

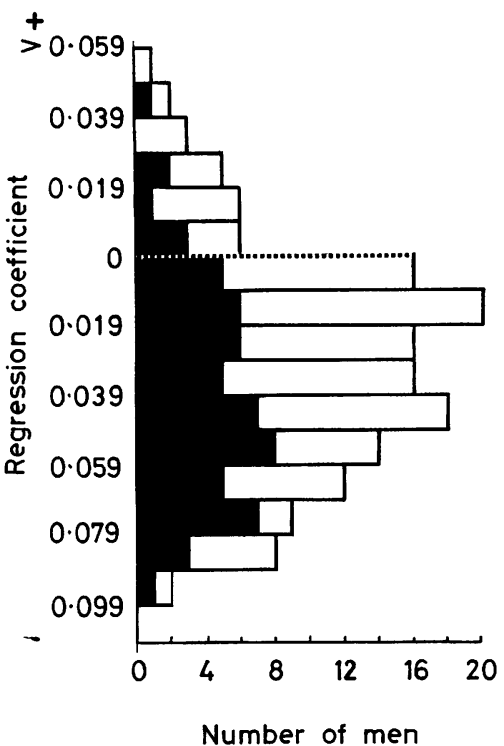

FIG. 1. Distribution of regression coefficients $\left(\mathrm{FEV}_{\mathbf{0 . 7 5}}\right.$ against time in litres/year) for 159 industrial workers.

Men with persistent morning or daily sputum for at least three months of the year.

TABLE 2

Change of Symptoms in 159 Men during the Period of Study

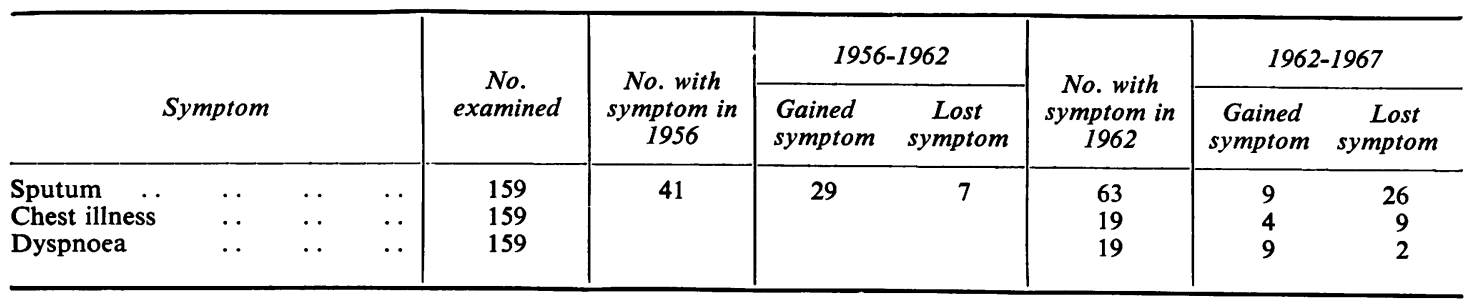


TABLE 3

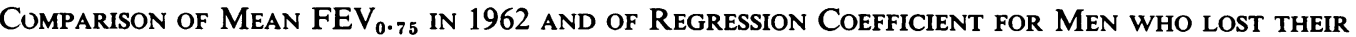

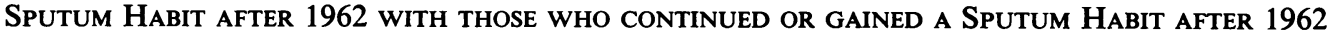

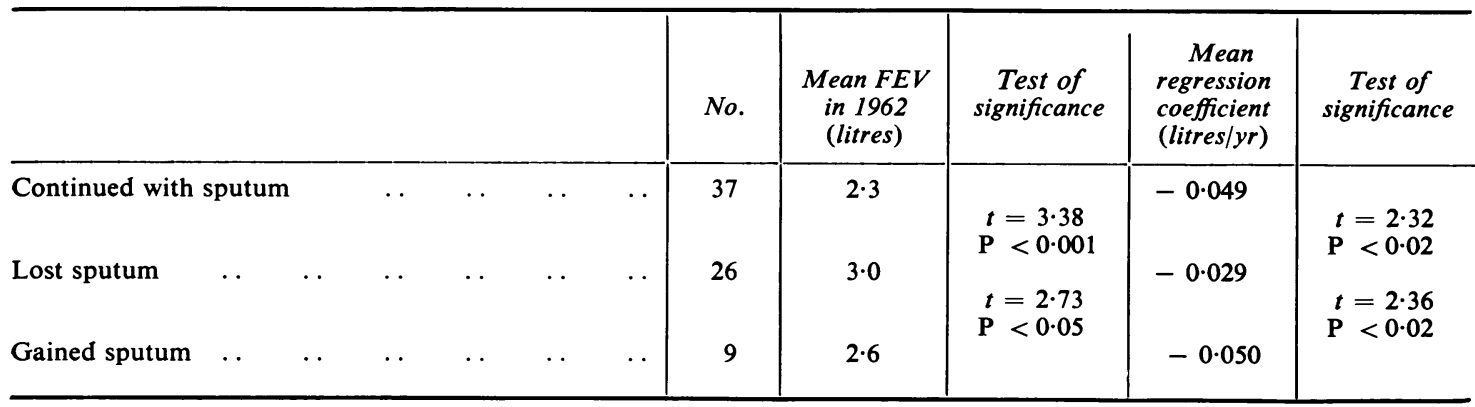

not entirely explained by the lower mean FEV of those with sputum. This does not necessarily indicate that the disease process responsible for sputum causes the loss of FEV. Men whose sputum ceased had a higher initial FEV and a smaller rate of fall of FEV than either those who acquired or continued throughout with a sputum habit. A similar trend was observed for chest illnesses and breathlessness but the numbers were too small for statistical evaluation.

The importance of sputum was considered in another way. The FEV graphs of the 38 men who acquired a sputum habit after 1956 were studied. It is difficult to draw a firm conclusion because of the few points available, but for 16 men the FEV was deteriorating at average or above average rates of fall for the whole group when sputum became established. In six it looked as though there could have been a sharp increase in the rate of decline after sputum appeared and in 16 there was no obvious change in FEV or it was not possible to draw a conclusion. Twenty-six men lost their sputum between 1962 and 1965 but as yet there has been no major improvement in the rate of loss of FEV.

Similar results were observed for chest illnesses. Thirty-one men claimed chest illnesses which kept them off work for two or more consecutive years between 1962 and 1967. These men, like those with sputum, had a lower FEV and a higher rate of decline $(-0.053$ litre/year $)$ than those without symptoms. Only 9 men acquired a history of regular chest illnesses but in 6 of these the FEV was already below normal and clearly deteriorating by the time the symptom appeared.

Table 4 shows that a sputum habit can be established at all levels of the FEV, both normal and abnormal. Many persons had lost considerable ventilatory capacity before the symptom appeared. If, however, those with milder disease more readily shed their symptoms, it would be expected that in
TABLE 4

Value of FEV at Which 38 Men acQuired a Regular Sputum Habit

\begin{tabular}{|c|c|c|c|c|c|c|c|}
\hline \multicolumn{7}{|c|}{$\begin{array}{c}F E V_{0.75} \\
\quad \text { (litres) }\end{array}$} & $\begin{array}{c}\text { No. } \\
1\end{array}$ \\
\hline $\begin{array}{l}1 \cdot 00-1 \cdot 25 \\
1 \cdot 26-1 \cdot 50 \\
1 \cdot 51-1 \cdot 75 \\
1 \cdot 76-2 \cdot 00 \\
2 \cdot 01-2 \cdot 25 \\
2 \cdot 26-2 \cdot 50 \\
2 \cdot 51-2 \cdot 75 \\
2 \cdot 76-3 \cdot 00 \\
3 \cdot 01-3 \cdot 25 \\
3 \cdot 26-3 \cdot 50 \\
3 \cdot 51-3 \cdot 75 \\
3 \cdot 76-4 \cdot 00\end{array}$ & $\begin{array}{l}\cdots \\
\cdots \\
\cdots \\
\cdots \\
\cdots \\
\cdots \\
\cdots \\
\cdots \\
\cdots \\
\cdots \\
\cdots\end{array}$ & $\begin{array}{l}\cdots \\
\ldots \\
\ldots \\
\ldots \\
\ldots \\
\ldots \\
\ldots \\
\cdots \\
\ldots \\
\cdots \\
\cdots\end{array}$ & $\begin{array}{l}\cdots \\
\cdots \\
\cdots \\
\cdots \\
\cdots \\
\cdots \\
\cdots \\
\cdots \\
\cdots \\
\cdots\end{array}$ & $\begin{array}{l}\cdots \\
\cdots \\
\cdots \\
\ldots \\
\ldots \\
\ldots \\
\ldots \\
\cdots \\
\ldots \\
\cdots\end{array}$ & $\begin{array}{l}\cdots \\
\cdots \\
\ldots \\
\ldots \\
\ldots \\
\ldots \\
\ldots \\
\ldots \\
\cdots \\
\cdots\end{array}$ & $\begin{array}{l}\cdots \\
\cdots \\
\cdots \\
\cdots \\
\ldots \\
\cdots \\
\cdots \\
\ldots \\
\cdots \\
\cdots\end{array}$ & $\begin{array}{l}1 \\
2 \\
0 \\
5 \\
6 \\
3 \\
2 \\
5 \\
1 \\
4 \\
6 \\
3\end{array}$ \\
\hline Total & . & $\cdots$ & . & $\cdots$ & . & $\cdots$ & 38 \\
\hline
\end{tabular}

more advanced stages the proportion of men with a regular sputum habit would steadily increase.

In conclusion the loss of FEV may be considerable before either persistent sputum or regular chest illnesses become established and it is considered unlikely that they were major factors in the decline of ventilatory capacity in this group of men.

\section{Mechanism of the decline of the FEV}

The individual graphs of the change of FEV with time were inspected. Large year to year variation $( \pm 10 \%)$ in the measurements of the FEV were not observed and in most men a steady rate of change of FEV was found throughout the study. In a few instances sudden drops of FEV were encountered and these looked similar to those already observed in hospital patients with bronchitis (Howard, 1967). The period of study was divided into three parts 1956-62, 1962-65, and 1965-67. A rate of fall of 
FEV at least four times greater than the mean for the whole group ( -0.034 litre/year) and certainly greater than a figure two standard deviations from this mean occurring during any one of these periods was considered a sudden drop of function. By the nature of the study only sudden drops of ventilatory capacity which did not recover would be detected. There were 27 of these episodes in 25 patients and Fig. 2 shows three examples. Twelve men had no symptoms of sputum, breathlessness or chest illnesses. The remainder had one or other of these symptoms. Seventeen smoked cigarettes, 4 were nonsmokers, and 4 ex-smokers or piper smokers, proportions which were not measurably different from those of the whole group of 159 men. Thus sudden falls of ventilatory capacity which do not recover may occur in symptomless men. They are a feature of all stages of the natural history of obstructive airways disease.

\section{Smoking habits}

The smoking habits of the whole group are shown in Table 5. Twenty-seven maintained they had never smoked and 100 men were regular cigarette smokers throughout the period of study. Exsmokers (18) were men who stopped smoking before 1966. Neither the initial FEV in 1956 nor the mean regression coefficients were statistically significantly different in any of the groups. However, an analysis of symptoms in the smoking groups (Table 6) showed that a persistent daily sputum habit in 1962 or at any time during the period 1962-67 was more likely to be present in those who smoked. But occasional or regular winter chest illnesses seemed not to be related to the smoking habit. Sputum expectoration ceased in 26 men but this could not be related to a change in smoking habits as less than a quarter changed their smoking regime. Thus, despite the association between smoking and sputum expectoration, there was no related effect on the regression coefficient, suggesting that neither
TABLE 5

MEAN FEV . $75_{\text {Regression COEFFICIENT IN }}$ RELATION TO SMOKING Habit

\begin{tabular}{lc|c|c|c}
\hline \multicolumn{1}{c|}{ Smoking habit } & No. & $\begin{array}{c}\text { Mean } \\
\text { FEV 1956 } \\
\text { (litres) }\end{array}$ & $\begin{array}{c}\text { Mean } \\
\text { regression } \\
\text { coefficient } \\
\text { (litres/yr) }\end{array}$ \\
\hline Non-smokers &.. & 27 & 3.2 & -0.036 \\
Ex-smokers .. &. & 18 & 2.7 & -0.025 \\
Pipe smokers.. &. & 14 & 3.0 & -0.037 \\
Cigarette smokers &.. & 100 & 3.0 & -0.031 \\
\hline Total &. & 159 & 3.0 & -0.034 \\
\hline
\end{tabular}

sputum nor smoking were associated with the loss of ventilatory capacity.

\section{Discussion}

This is a study of a volunteer group of men from an industrial environment. Every effort was made to sample a wide range of occupation within the company and all men lived within a radius of a few miles. It was hoped by the use of a prospective study to investigate the evolution of symptoms and respiratory function in chronic bronchitis. The major disadvantage of this long-term study was the problem of maintaining contact with the original group. During the period of 11 years natural wastage and internal reorganizations within the company resulted in the loss of about one-third of the group to follow-up. Every effort was made to keep in contact with the disabled men who left the company, in order that the group finally untraced did not contain an undue proportion of these persons.

Patients who attend hospital with chronic bronchitis are usually so breathless that they are unable to walk on the level at a normal pace or do manual work. They often give a long history of
T.M.

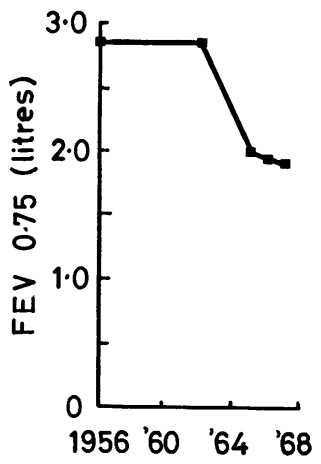

M.G.

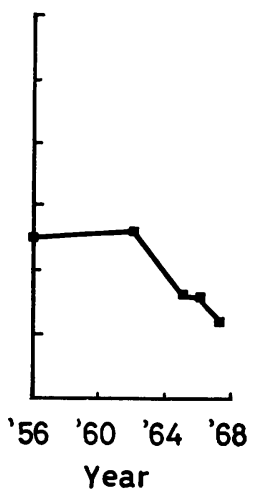

G.C.K.

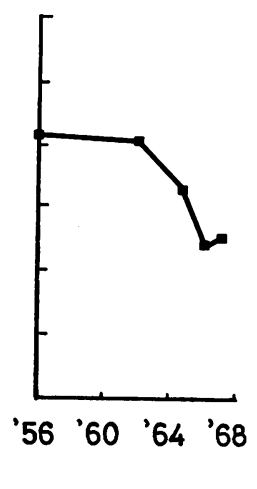

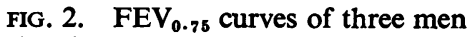
showing a sudden loss of ventilatory function.

T.M. and M.G. were both foundry workers having regular sputum and winter illnesses. G.C.K. was quite symptomless in a clerical job. 
TABLE 6

Respiratory Symptoms in Relation to SMOKING Habit

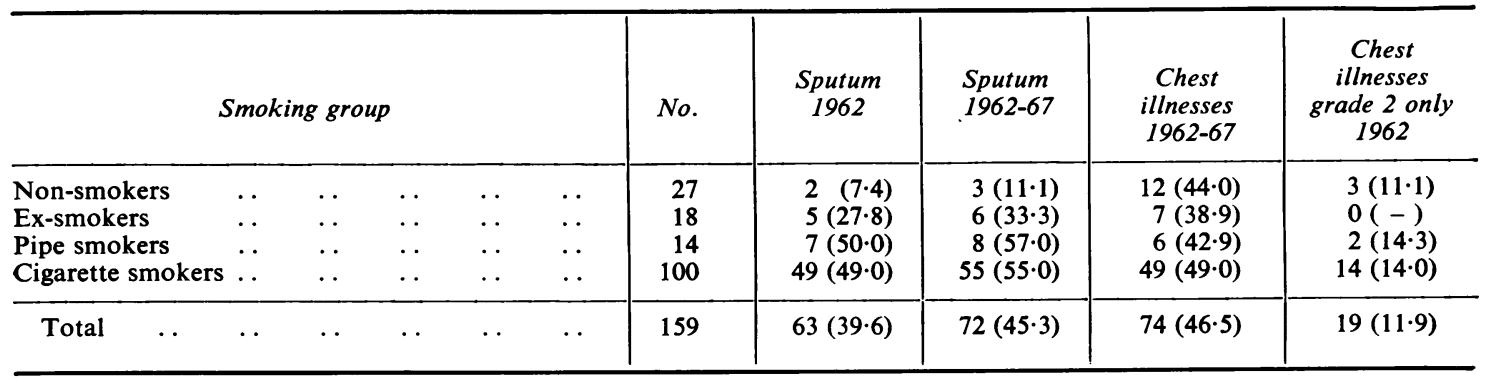

Percentages are shown in parentheses.

Significance tests, Sputum 1962: $\quad$ Smokers $v$ non-smokers $P<0.001$

Ex-smokers $v$ smokers $\mathrm{P}=0.05$

Sputum 1962-67: Smokers $v$ non-smokers $\mathrm{P}<0.001$

Ex-smokers $v$ smokers $P<0.05$

Pipe smokers $v$ smokers N.S. for all symptoms

Non-smokers and ex-smokers $v$ smokers, N.S. for chest illnesses.

productive cough and winter illnesses. At the time when this investigation started (1956) many physicians believed that the sputum production and winter illnesses represented inflammation and infection leading to narrowing of the bronchi which both preceded and caused the breathlessness. It became apparent, however, with the first prevalence studies (Higgins, 1957; Fletcher et al., 1959) and in this study in 1956 that many patients who denied sputum and chest illnesses nevertheless had ventilatory impairment as shown by the FEV. American authors had always maintained that their patients became breathless and suffered impairment of ventilatory capacity without a comparable incidence of sputum and chest illnesses. But these views were subsequently modified after a Chicago-London comparison (Fletcher, Jones, Burrows, and Niden, 1964). Cigarette smoking (Oswald, Harold, and Martin, 1953; Oswald and Medvei, 1955; Ogilvie and Newell, 1957; Higgins, 1959; Fletcher et al., 1959), occupation (Pemberton, 1956; Higgins, 1957), and atmospheric pollution (Holland and Reid, 1965; Holland, Reid, Seltser, and Stone, 1965; Fairbairn and Reid, 1958; Phelps and Koike, 1962) were associated with an increased incidence of symptoms and a lower FEV. But it was not possible to decide which of these factors was primarily associated with structural damage to the lung. Pathologists (Leopold and Gough, 1957; Heppleston, 1968; McLean, 1958) have maintained that specimens they examine show active inflammatory disease of the airway, particularly around the respiratory bronchioles, and this is important in the aetiology of at least some forms of lung damage. By the nature of their studies, material was usually obtained from established cases of disease and it was impossible to be sure that inflammatory processes did not arise in areas of lung already affected by other factors. Thus the importance of bronchial inflammation and infection and its relationship to the other factors of smoking, occupation, and environment remain unresolved.

In this study the evolution of symptoms and the decline of the FEV have been studied independently. The change in sputum habit and the frequency of chest illnesses since 1962 is striking, but the improvement is in accord with the findings of Fletcher (1967) in London workers.

The mean rate of decline of the FEV of 0.034 litre/year compares with a value of 0.026 litre/year found by Fletcher (1968) for 904 men in London and 0.031 litre/year found by Rosenzweig et al. (1966) in a normal population. Age correlations of normal populations have produced figures of 0.025 litre/year (Kory, Callahan, Boren, and Syner, 1961) and 0.024 litre/year (Ferris, Anderson, and Zinkmantel, 1965). Higgins and Oldham (1962), in a five-year follow-up of miners, obtained values of 0.052 litre/year for smokers and 0.024 litre/year for non-smokers. A study of patients with bronchitis attending hospital in Sheffield (Howard, 1967) gave a mean figure of -0.083 litre/year. A comparison of the frequency distribution of regression coefficients for this working population of 159 men compared with established bronchitics attending hospital (Fig. 3) showed the hospital patients to be predominantly at the more rapidly deteriorating end of the spectrum. Hospital patients are a select group on the grounds of greater or more rapid loss of ventilatory capacity.

The greater fall of the FVC over the FEV seemed largely due to its greater value. There was surprisingly little change of FEV \% FVC throughout the period 


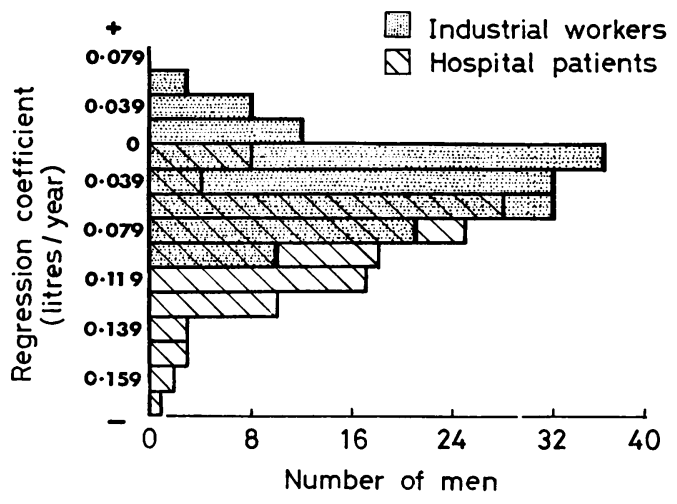

FIG. 3. Comparison of the frequency distribution of regression coefficients (of FEV against time in litres/year) for the group of industrial workers described in this study and a group of hospital patients with well-established chronic bronchitis in the same city.

of study. Thus both FEV and FVC deteriorated simultaneously and there was no evidence to suggest the decline in one factor occurred before changes in the other. The FVC is probably reduced by a number of mechanisms, plugging or fibrotic occlusion of airways, premature closure during forced expiration, very high resistance in individual airways and, in later stages, fixation of the chest wall in inspiratory positions. In broad terms these mechanisms can be considered 'obstructive' in nature except perhaps for the chest wall changes. Most of these changes can also limit flow by creating resistance when the patient expires rapidly. A closer analysis of the changes of FEV compared to FVC is needed but it is suggested that airway disease causing 'obstruction' results in simultaneous changes in FEV and FVC perhaps due to differences in severity of disease in individual airways.

Men whose ventilatory capacity is lower or

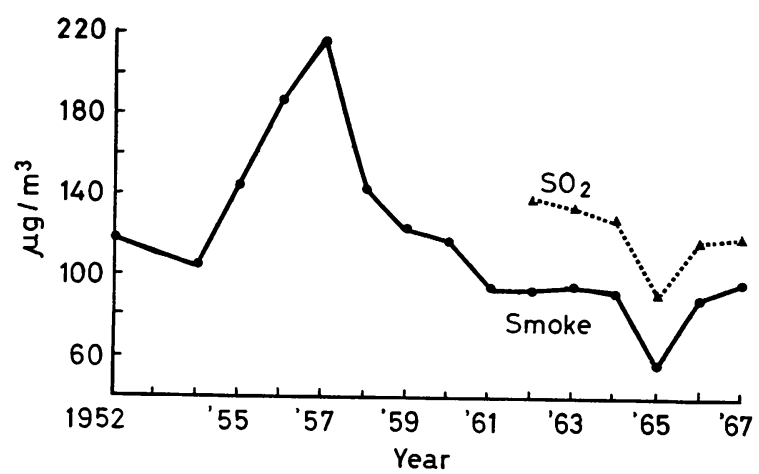

deteriorating rapidly tend to have a greater incidence of symptoms, particularly of sputum expectoration and chest illnesses. The evidence presented suggests that these symptoms are largely coincidental with the loss of FEV rather than associated with its cause. The assumption that hospital patients with bronchitis must have had symptoms for long periods before the onset of deterioration in ventilatory capacity is not supported. Other studies have also failed to show a definite connection between sputum expectoration and acute chest illnesses with the loss of FEV (MRC Chemotherapeutic Trial, 1966; Fletcher, 1968; Howard, 1967; Calder, Lutz, and Schonell, 1968). But in individual cases sharp falls of FEV have been observed following acute chest illnesses involving expectoration of sputum (Howard, 1967). Clearly the precise role of bronchial infection is not yet fully elucidated. It is unlikely to be a major factor when considering large groups of persons, and other mechanisms must be important.

Cigarette smoking has been suggested but little support is obtained from this study. Smokers and non-smokers did not have different absolute levels of the FEV. This contrasts with the findings of (Fletcher et al., 1959; Fletcher and Tinker, 1961; Higgins, 1959), and many other studies. Neither did the smokers and non-smokers have different rates of decline of the FEV despite the symptom differences. This again contrasts with the findings of Fletcher (1968) and Higgins and Oldham (1962).

If smoking and sputum habit cannot easily be related to the decline of the FEV in this group of men, there must be other relevant factors. These men live in a heavily polluted area. Twenty years ago average yearly smoke concentrations in the city of Sheffield exceeded $500 \mu \mathrm{g} / \mathrm{m}^{3}$. Figure 4 shows the available data for atmospheric smoke and sulphur dioxide during the course of the study from a collecting station close to the works. The average yearly smoke concentration doubled during the early part of the study when the increased incidence of symptoms was observed. The recent improvement

FIG. 4. Average yearly levels of atmospheric smoke and sulphur dioxide $\left(\mathrm{SO}_{2}\right)$ taken from a sampling station close to the works. 
in symptoms coincided with a return of the levels of atmospheric smoke to pre-study levels. The importance of atmospheric pollution to respiratory symptoms and the FEV has been emphasized by Fairbairn and Reid (1958) and Holland and Reid (1965). Lunn, Knowelden, and Handyside (1967) found in Sheffield schoolchildren that atmospheric pollution had an important effect on the incidence of respiratory illnesses. If the respiratory disability in adults is due to a combination of several causes, such as cigarette smoking, recurrent infection, and atmospheric pollution, then one might expect each to contribute. But if one factor alone is sufficient to cause a maximal response then it would not be possible to detect any contribution from the other possible causes. This study suggests that heavy atmospheric pollution, to which all these men were exposed, was causing a maximal response and was making it impossible to detect the contribution of cigarette smoking or repeated infections. Carefully controlled prospective studies with groups in different environments might make it possible to detect the contribution of these other factors.

Finally, in view of the variable rate of decline of the FEV in individual men, it is difficult to determine what should be considered a normal rate of deterioration. The selection of a 'normal' population by the absence of symptoms is clearly erroneous and likely to include many men who are deteriorating rapidly but yet asymptomatic. For these reasons the figures of 'normal' regression coefficients for the FEV obtained from prevalence studies and hospital populations are too high.

I am grateful to Professor Sir C. H. Stuart-Harris, M.D., F.R.C.P. for his encouragement of this work and to Miss V. Home for expert technical assistance. The management and employees of Newton Chambers and Co. Ltd. were always most willing and helpful in their participation and I am very grateful to them. The work was supported in part by a grant from the Endowment Fund of the United Sheffield Hospitals.

\section{References}

Brinkman, G. L., and Coates, E. O. (1963). The effect of bronchitis, smoking, and occupation on ventilation. Amer. Rev. resp. Dis., 87, 684-693.

Calder, M. A., Lutz, W., and Schonell, M. E. (1968). A five year study of bacteriology and phophylactic chemotherapy in patients with chronic bronchitis. Brit. J. Dis. Chest, 62, 93-99.

Ciba Guest Symposium (1959). Terminology, definitions and classification of chronic pulmonary emphysema and related conditions. Thorax., 14, 286-299.

Elmes, P. C., Dutton, A. A.C., and Fletcher, C. M. (1959). Sputum examination and the investigation of 'chronic bronchitis'. Lancet, 1, 1241-1244.

Fairbairn, A. S., and Reid, D. D. (1958). Air pollution and other local factors in respiratory disease. Brit. J. prev. soc. Med., 12 , 94-103.
Ferris, B. G., Anderson, D. O., and Zinkmantel, R. (1965). Prediction values for screening tests of pulmonary function. Amer. Rev. resp. Dis., 91, 252-261.

Fletcher, C. M. (1967). Recent clinical and epidemiological studies of chronic bronchitis. Scand J. resp. Dis., 48, 285-293.

(1968). Bronchial infection and reactivity in chronic bronchitis. J. roy. Coll. Physcns Lond., 2, 183-190.

- Elmes, P. C., Fairbairn, A. S., and Wood, C. H. (1959). The significance of respiratory symptoms and the diagnosis of chronic bronchitis in a working population. Brit. med. J., 2, 257-266.

_, Jones, N. L., Burrows, B., and Niden, A. H. (1964). American emphysema and British bronchitis. A standardized comparative study. Amer. Rev. resp. Dis., 90, 1-13.

, and Tinker, C. M. (1961). Chronic bronchitis-a further study of simple diagnostic methods in a working population. Brit. med. $J ., 1,1491-1498$.

Heppleston, A. G. (1968). Lung architecture in emphysema. In Form and Function in the Human Lung. Edited by Cumming, G., and Hunt, L. B., pp. 6-19. Livingstone, Edinburgh.

Higgins, I. T. T. (1957). Respiratory symptoms, bronchitis, and ventilatory capacity in random sample of an agricultural population. Brit. med. J., 2, 1198-1203.

(1959). Tobacco smoking, respiratory symptoms, and ventilating capacity. Brit. med. J., 1, 325-329.

, and Oldham, P. D. (1962). Ventilatory capacity in miners: A five-year follow-up study. Brit. J. industr. Med., 19, 65-76.

Holland, W. W., and Reid, D. D. (1965). The urban factor in chronic bronchitis. Lancet, 1, 445-448.

,$-\frac{1}{-}$ Seltser, R., and Stone, R. W. (1965). Respiratory disease in England and the United States. Studies of comparative prevalence. Arch. environm. Hlth, 10, 338-343.

Howard, P. (1967). Evolution of the ventilatory capacity in chronic bronchitis. Brit. med. J., 3, 392-395.

Kory, R. C., Callahan, R., Boren, H. G., and Syner, J. C. (1961). The Veterans Administration - Army cooperative study of pulmonary function. 1. Clinical spirometry in normal men. Amer. J. Med., 30, 243-258.

Leopold, J. G., and Gough, J. (1957). The centrilobular form of hypertrophic emphysema and its relation to chronic bronchitis. Thorax, 12, 219-235.

Lunn, J. E., Knowelden, J., and Handyside, A. J. (1967). Patterns of respiratory illness in Sheffield infant schoolchildren. Brit. J. prev. soc. Med., 21, 7-16.

McKerrow, C. B., McDermott, M., and Gilson, J. C. (1960). A spirometer for measuring the forced expiratory volume with a simple calibrating device. Lancet, 1, 149-151.

McLean, K. H. (1958). The pathogenesis of pulmonary emphysema. Amer. J. Med., 25, 62-74.

Medical Research Council (1960). Standardized questionnaires on respiratory symptoms. Brit. med. J., 2, 1665.

(1965). Definition and classification of chronic bronchitis for clinical and epidemiological purposes. Lancet, 1, 775-779.

(1966). Report of the working party on trials of chemotherapy in early chronic bronchitis. Brit. med. J., 1, 1317-1322.

Ogilvie, A. G., and Newell, D. J. (1957). Chronic Bronchitis in Newcastle-upon-Tyne. Livingstone, Edinburgh.

Oldham, P. D. (1962). A note on the analysis of repeated measurements of the same subjects. J. chron. Dis., 15, 969-977.

Oswald, N. C., Harold, J. T., and Martin, W. J. (1953). Clinical pattern of chronic bronchitis. Lancet, 2, 639-643.

, and Medvei, V. C. (1955). Chronic bronchitis. The effect of cigarette-smoking. Lancet, 2, 843-844.

Pemberton, J. (1956). Chronic bronchitis, emphysema, and bronchial spasm in bituminous coal workers. Arch. industr. Hyg., 13, 529-544.

Phelps, H. W., and Koike, S. (1962). 'Tokyo-Yokohama asthma.' Amer. Rev. resp. Dis., 86, 55-63.

Registrar General's Decennial Supplement (England and Wales) 1951. Life Tables, pp. 31-32.

Rosenweig, J. A., Atkins, J. A., and Schrock, L. G. (1966). Ventilation studies on a normal population after a seven year interval. Amer. Rev. resp. Dis., 94, 74-77.

Stuart-Harris, C. H., and Hanley, T. (1957). Chronic Bronchitis, Emphysema and Cor Pulmonale. Wright, $\mathrm{B}_{1}$ istol.

Received for publication February 3, 1970 